\title{
Social and Non Social Media Users During The COVID- 19 Pandemic Confinement Period in Canada: The "Plugged-In", Unplugged and Other Population Segments ${ }^{1}$
}

\author{
Fernando Mata \\ School of Sociological and Anthropological Studies, University of Ottawa, Canada, \\ E-mail: fmata@uottawa.ca
}

Jennifer Dumoulin

Department of Communication, University of Ottawa

E-mail: jdumo098@uottawa.ca

November 23, 2020

Keywords: Social and Non Social Media Users, Market Segmentation, COVID-19 Pandemic, Canada

\begin{abstract}
Canadians are using a variety of social and non-social media vehicles to gather information, share experiences and express anxieties during the COVID-19 confinement period. The purpose of the study is to produce a portrait of media use in Canada, paying special attention to the typical population segments in the Canadian population differentiated by their media vehicles and sources of information about the pandemic. The study used as its data source a survey sample of 4,600 adult Canadians aged 15 years old and over during the period of July 20-26 2020, and collected by Statistics Canada. Media user activities comprised a set of 11 dichotomous scales collecting data on main sources of information such as social media posts, online news, online magazines, video platforms, e-mails as well as non internet-based sources. A market segmentation analysis of these scales using Principal Components and $\mathrm{k}$-means cluster analysis revealed the presence of six major population segments: Social Media Buffs (27\%), News Followers (33\%), Unplugged (10\%),Plugged-In (7\%), E-Mailers (7\%) and Mixed Source Users (16\%). The segment mottos were as follows: "Social Media Influencers Know Their Stuff!", "Track Those Headlines!", "I’ve Got My Own Info Sources About The Pandemic!", "Did You Read The Last Blog?" "My People Know Better!" and "Better Info Means More Choices!". This study suggests that media users in Canada constitute a very diverse group of individuals who are engaged in social and non social media to obtain timely information about the pandemic. However, they can also be exposed to inaccurate, misleading information about the virus, its transmission and its treatments. In this light, market segmentation may be a useful tool for decision makers to categorize population members by their typical attitudinal traits and, by doing so, facilitate better public campaigns directed at population segments, help design messages,
\end{abstract}

\footnotetext{
I Paper to be presented at the 2021 CSA Meetings, Edmonton-Alberta. The authors would like to thank Stein Monteiro, the Ontario Data Documentation, Extraction Service and Infrastructure (ODESI-Scholars Portal Statistics) as well as Statistics Canada for making available the data and valuable support and guidance.
} 
and implement changes that can promote more efficient ways to deal with their target audiences.

\subsection{Background}

The COVID-19 virus has caused major disruptions across the world, after being declared as a pandemic by the World Health Organization (WHO) on January 312020 (WHO, 2020). This pandemic has led to several disruptions for most of the world's population. In Canada, the first cases of infections were observed in travellers from China ${ }^{2}$ and reported to the press in January 2020. Given a steady climb in cases, on March 25 2020, an emergency aid bill passed and Canada made 14-day quarantine mandatory for all arrivals. Three days later Prime Minister Trudeau announced a ban on air travel for those with COVID-19 symptoms. Canada is presently undergoing the so-called "second" phase. As of October 25 2020, there had been a total of 9,946 deaths attributed to the COVID-19 virus in Canada ${ }^{3}$. A larger number is expected in the coming months. Most of the reported cases are in Canada's two most populous provinces, Ontario and Quebec, which have declared different sanitary measures and confinement restrictions to deal with virus spread in the population.

With limited opportunities for social interaction and an increase in the amount of time spent in the home, Canadians are spending more time on the internet, watching television and closely following on-line news ${ }^{4}$. While both digital and non-digital media can contain inaccurate or misleading information, the availability of such information on the internet is growing at an exponential rate. They have become critical sources of information during crises situations such as the current COVID-19 emergency occurring in Canada (Drouin, 2020; Weiderhold, 2020). Through them, individuals gather necessary information, follow developments and sanitary guidelines, seek social support and/or express anxieties about traumatic events New technologies now offer both younger and older audiences alternative communication opportunities from those offered by traditional media such as newspapers, radio and T.V. (Valkenburg and Piotrowski, 2017). The choice of a particular information vehicle (digital or a more traditional one), however, depends on multiple factors including the appeal of a particular communication technology, social settings and media presence, familiarity with a particular medium and personal factors such as the generational cohort to which the individual belongs such as Generation Z, Generation X, Baby Boomers, etc. (see WEF, 2019)

Social media vehicles, in particular, comprise a wide spectrum of possibilities in terms of communication exchanges. Online social media news platforms, for instance, allow readers to be informed of breaking news as well as the ability to easily and quickly share this information with family and friends. Social media influencers make regular posts about a topic on their preferred social media channels (e.g. YouTube, Instagram). Online magazines (also called "Webzines") and encyclopedias distribute interesting information materials on a regular basis in their respective areas of expertise. Podcasts (digital audio files) can also be received by subscribers while e-mails, which are often of a more personal nature, are distributed by electronic means from one computer user to one or more recipients via a network. Video-based

\footnotetext{
2 Source: https://nationalpost.com/pmn/news-pmn/canada-news-pmn/timeline-of-covid-19-cases-incanada-2.

3 Source: https://www.statista.com/statistics/1107079/covid19-deaths-by-province-territory-canada.

4 Source: https://www150.statcan.gc.ca/n1/daily-quotidien/200817/dq200817b-eng.htm
} 
platforms such as TikTok are popular during the confinement period because they enable users to upload, convert, store and play back video content on the Internet. Zoom, Skype and Google Hangouts, and other real-time videoconferencing platforms have replaced in-person meetings in professional and personal settings. Online discussion forums and online blogs (e.g. Twitter, Tumblr, Reddit) are also popular online discussion sites allowing people to hold conversations in the form of posted messages. It should be noted, however, that information regarding the COVID-19 pandemic is not necessarily limited to social media vehicles as many Canadians prefer also to use more traditional sources of news such as T.V., radio, the printed press as well as personal contacts which are deemed as the more "reliable" sources available to the individual.

In this study, marketing segmentation is used to identify population segments who share commonalities in terms of the type of media use and information sources about the pandemic situation in Canada. Market segments are groups of individuals who are very similar in their reaction to one or more mix of environmental elements and, as such, can be targeted by public health and communication agencies aimed at promoting social well-being (Grover and Briens, 2006). In a typical psychographic segmentation analysis, for instance, individuals are divided into different groups on the basis of psychosocial and other behavioural characteristics (Lin, 2002). This technique divides the market into segments on the basis of interest, values, opinion, personality characteristics, attitudes using techniques of factor analysis, cluster analysis and canonical correlation (Tynan and Drayton, 1987).

Using a sample of the adult population of Canada, the central objectives of the marketing segmentation analysis undertaken here is to break down the population into meaningful clusters of individuals (homogeneous) in terms of their psychographic traits during the COVID-19 pandemic. Three central questions guided the segmentation analysis: 1) What information sources (from both social and non-social media) are the most commonly reported by Canadians during the pandemic? 2) Can groups of individuals be differentiated into attitudinal and/or behavioural segments or clusters according to their media use preference? and 3) What are the typical socio-demographic, residential, employment and other psychosocial characteristics of the members of these population segments? The CPSS-Series4 survey conducted by Statistics Canada was regarded as an ideal data source chosen to empirically explore these three central research questions and produce a statistical portrait of typical media users during the pandemic ${ }^{5}$.

\subsection{Sample and Measures}

The Canadian Perspective Survey Series4 (CPSS Series4) entitled "Information Sources Consulted During the Pandemic" is a voluntary online survey that collected information on knowledge and behaviours of approximately 4,600 Canadians aged 15 years old and over who were residents of the 10 Canadian provinces. It was administered by Statistics Canada between July 202020 and July 262020 (the reference week). The probability panel of the CPSS-Series1 was created by randomly selecting a subset of the Labour Force Survey (LFS) respondents. The CPSS Series4 survey collected a wide range of information on health impacts, checking information sources, precautions to avoid risks,

\footnotetext{
5 This study is the fourth market segmentation study carried out using CPSS data. The first one, focusing on routine activities which used CPSS-Series2 data, is available at: https://osf.io/preprints/socarxiv/6vumh/
} 
routine activities and others ${ }^{6}$.

A total of 11 social media use dichotomous item scales were used for this analysis. These tapped into the usage of social and non-social media sources for obtaining information on the COVID-19 pandemic in Canada. Scales were measured as $0=$ No and $1=$ Yes. The following general question was asked in the CPSS Series4 survey: Since the beginning of the COVID-19 pandemic, which of the following online sources have you used to find information on COVID19? (list provided). The roster of information sources scales ranked by their average scale scores is presented in Table 1 . The most frequently mentioned sources were Online News (63\%), Social Media News (35\%) and Social Media Influencers (30\%). As expected, the use of non-internet sources was negatively correlated with all items related with internet-based social media use. Combinations of utilization of these information sources were also observed. The highest positive correlations were found between the social influencers source and online news use $(r=.27)$ and online magazine and online news use $(r=.17)$.

\subsection{Statistical Methods and Segment Identification}

Principal Component Analysis (PCA) and k-means cluster analysis were used as the main statistical techniques for segment identification (see detail of the methodologies followed in Punj and Stewart (1983), Grover and Vriens (2006) and Salkind and Rasmussen (2010). In the first phase, Principal Components (statistical technique aimed at data reduction) extracted 4 major dimensions underlying information contained in the 11 scales of social media use related items. In the second phase, using component scores of these dimensions capturing 51\% of the total data variation, $\mathrm{k}$ means clustering analysis was applied to the CPSS-Series1 data. This clustering algorithm was developed to sort survey respondents into a $\mathrm{k}$ number of clusters through assignments and reassignments based on the shortest distance between the individual and the centroid (mass centre) of the cluster. The distance measure chosen for this purpose was the Euclidean distance squared. For the cluster analysis $\mathrm{k}=2$ to $\mathrm{k}=8$ segment solutions were tested. The $\mathrm{k}=6$ solution proved to be the most valid and informative according to the parsimonious reduction of the Within Sum of Squares (WSS) and the application of the "elbow" criteria as a stopping rule in the partition of clusters (see technical appendix chart A-1).

The validation of the partition of the population into six clusters was verified using Analysis of Variance (ANOVA) F tests where the cluster membership was used in the prediction of the sociodemographic and attitudinal characteristics of respondents (see table A-2 in the technical appendix). The highest predicted power of the cluster partition was found in reference to the age group of individuals ( $7 \%$ of variance explained).

\footnotetext{
6 Statistics Canada has already released major findings of the CPSS-Series1, Series 2 and CPSS-3 surveys (conducted between March 29-April 32020 and June 15-21 2020 respectively), which include: greater anxieties over personal health and the health of others, that most Canadians were following health guidelines, greater time spent on the internet and watching television, women were stricter in terms of following guidelines than men, and youth were less likely to wear masks in public. Sources : 1) https://www150.statcan.gc.ca/n1/daily-quotidien/200408/dq200408c-eng.htm; 2) https://www150.statcan.gc.ca/n1/daily-quotidien/200708/dq200708a-eng.htm.
} 
Table 1: Average Score of Information Sources Scales Ranked by Their Greater Frequency of Reporting, Canadian Adults, 2020

\begin{tabular}{|r|l|r|r|}
\hline $\begin{array}{c}\text { Item } \\
\text { Number }\end{array}$ & \multicolumn{1}{|c|}{$\begin{array}{c}\text { Information Source Scales: } \\
\text { Percent (\%) using: }\end{array}$} & $\begin{array}{c}\text { Mean of } \\
\text { Scale } \\
\text { Score }\end{array}$ & $\begin{array}{c}\text { Std. } \\
\text { Deviation }\end{array}$ \\
\hline 1 & Online News & $\mathbf{6 3 \%}$ & $\mathbf{4 8 \%}$ \\
2 & Social Media News & $\mathbf{3 5 \%}$ & $\mathbf{4 8 \%}$ \\
3 & Social Media Influencers & $\mathbf{3 0 \%}$ & $\mathbf{4 6 \%}$ \\
4 & Non-Internet Sources & $\mathbf{1 0 \%}$ & $\mathbf{3 0 \%}$ \\
5 & Online Magazines & $\mathbf{9 \%}$ & $\mathbf{2 8 \%}$ \\
6 & Video Platforms & $\mathbf{9 \%}$ & $\mathbf{2 8 \%}$ \\
7 & Online Forums & $\mathbf{5 \%}$ & $\mathbf{2 2 \%}$ \\
9 & E-mails & $\mathbf{5 \%}$ & $\mathbf{2 2 \%}$ \\
10 & Podline Encyclopedias & $\mathbf{4 \%}$ & $\mathbf{1 9 \%}$ \\
11 & Online Blogs & $\mathbf{4 \%}$ & $\mathbf{1 9 \%}$ \\
& & $\mathbf{1 \%}$ & $\mathbf{1 2 \%}$ \\
\hline
\end{tabular}

Source: CPSS-Series4 Survey, Statistics Canada, 2020

\subsection{Findings}

\subsection{Segment Prevalence and Traits}

According to the cluster analysis of the CPSS-Series4 data, six uniquely profiled groups of the Canadian adult population respondents were identified. Their membership was distributed as follows: $27 \%$ in segment $1,33 \%$ in segment $2,10 \%$ in segment $3,7 \%$ in segment $4,7 \%$ in segment 5 and $16 \%$ in segment 6 . Based on the social media use profiles drawn from the item scales, the segments were labeled as follows: Segment 1 - "Social Media Buffs", Segment 2-"News Followers", Segment 3-"Unplugged", Segment 4-"Plugged In", Segment 5-"E-mailers" and Segment 6 "Mixed Source Users". The prevalence ${ }^{7}$ (adult population \% share) of these segments is presented in pie chart 1.

7 Population estimates were obtained using weighted frequencies. 
Chart 1: Segment Prevalence in the Canadian Adult Population during the COVID19 Pandemic, Media User Items, Canadians Aged 15 years Old and Over

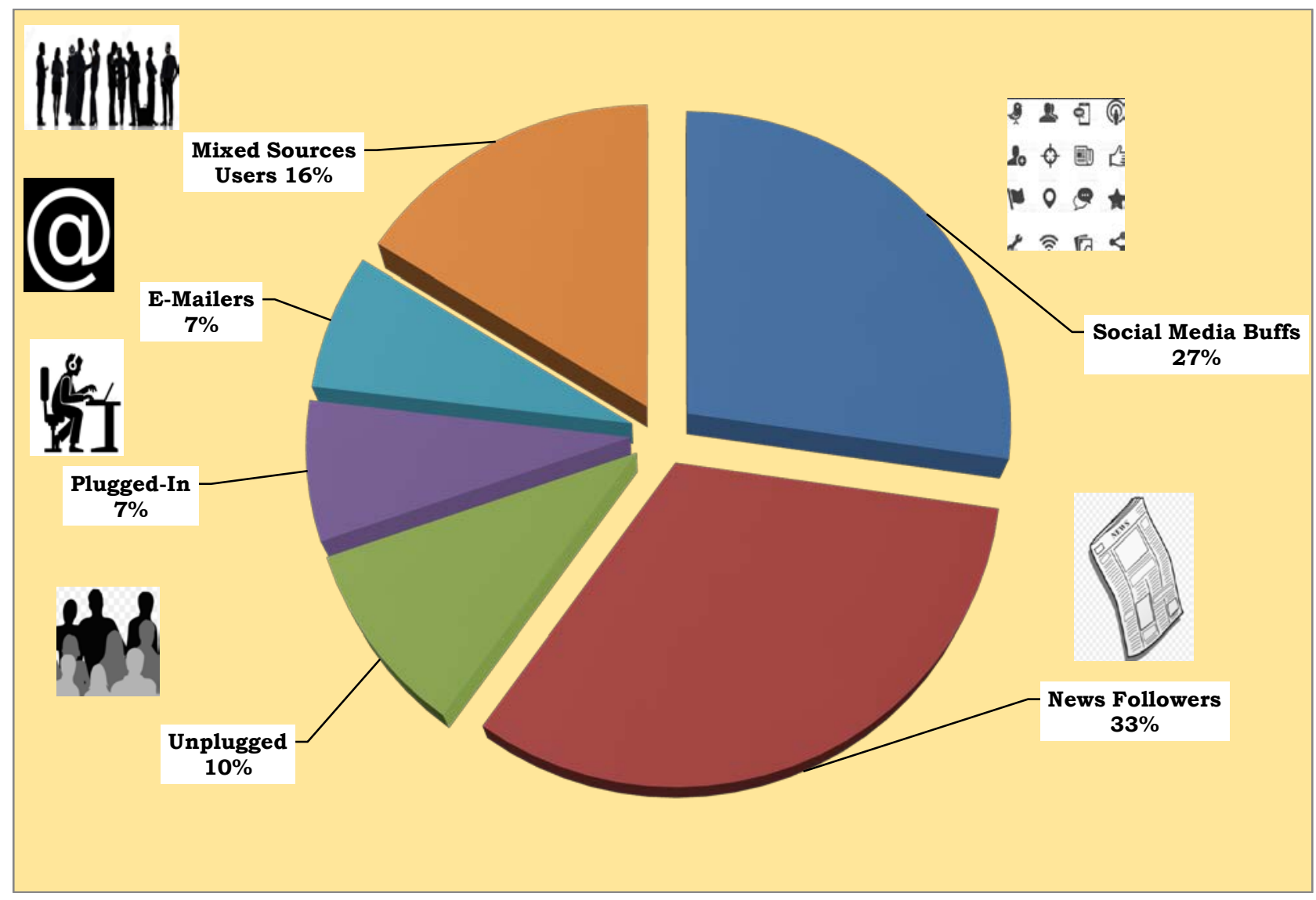

Source: CPSS-Series4 Survey, Statistics Canada, 2020

A visual representation (PCA bi-plot) of the vector of social media use items and dimensions underlying the data are displayed in chart 2. The first two components extracted by PCA accounted for $32.1 \%$ of the variance of all items. The first dimension represented by $\mathrm{C} 1$ (17.5\% of the total variance of items) opposed as polar cases members of the Plugged-In to the Unplugged segments, revealing a digital vs. non-digital divide between social media users and those using more traditional sources of information. The second dimension, represented by $\mathrm{C} 2$ (14.6\% of the total variance of items), opposed Social Media Buffs and News Followers' members. This opposition reveals a dimension related to more passive involvement vs. more active involvement with social media. The biplot also reveals some interesting intra-group distinctions according to the specific medium used (e.g. online magazine vs. blogs vs. e-mails). 
Statistical Note: In the Chart 2 PCA bi-plot ${ }^{8}$, the first two principal components extracted from the data (C1 and $\mathrm{C} 2)$ are shown. They are the most fundamental dimensions summarizing the social media user activity patterns reported by respondents. In the biplot, vectors represent items which are presented as points in space. The bi-plot of the second component on the first component is useful as it displays the correlations of variables in terms of various item vectors of different magnitudes, directions and positions. Proximity of user activity traits to group positions in space suggests an over-representation of these traits with respect to the composition of groups while greater distances suggests its converse. Correlations between two indicator variables in component space are equal to the cosines of the angles between the indicator vectors $(\theta)$, or $r=\cos (\theta)$. Highly correlated variables are located at sharp angles from each other $(\theta=90$ degrees or less) while those zero correlated are "orthogonal" to each other $(\theta=90$ degrees). If variables are perfectly negatively correlated, then $\theta=360$ degrees (vector in opposite direction).

8 PCA biplots were obtained using XLStat as statistical software. 
Chart 2: Biplot of Media Use Items and Population Segment Positions during the COVID-19 Pandemic, Canadians Aged 15 Years Old and Over

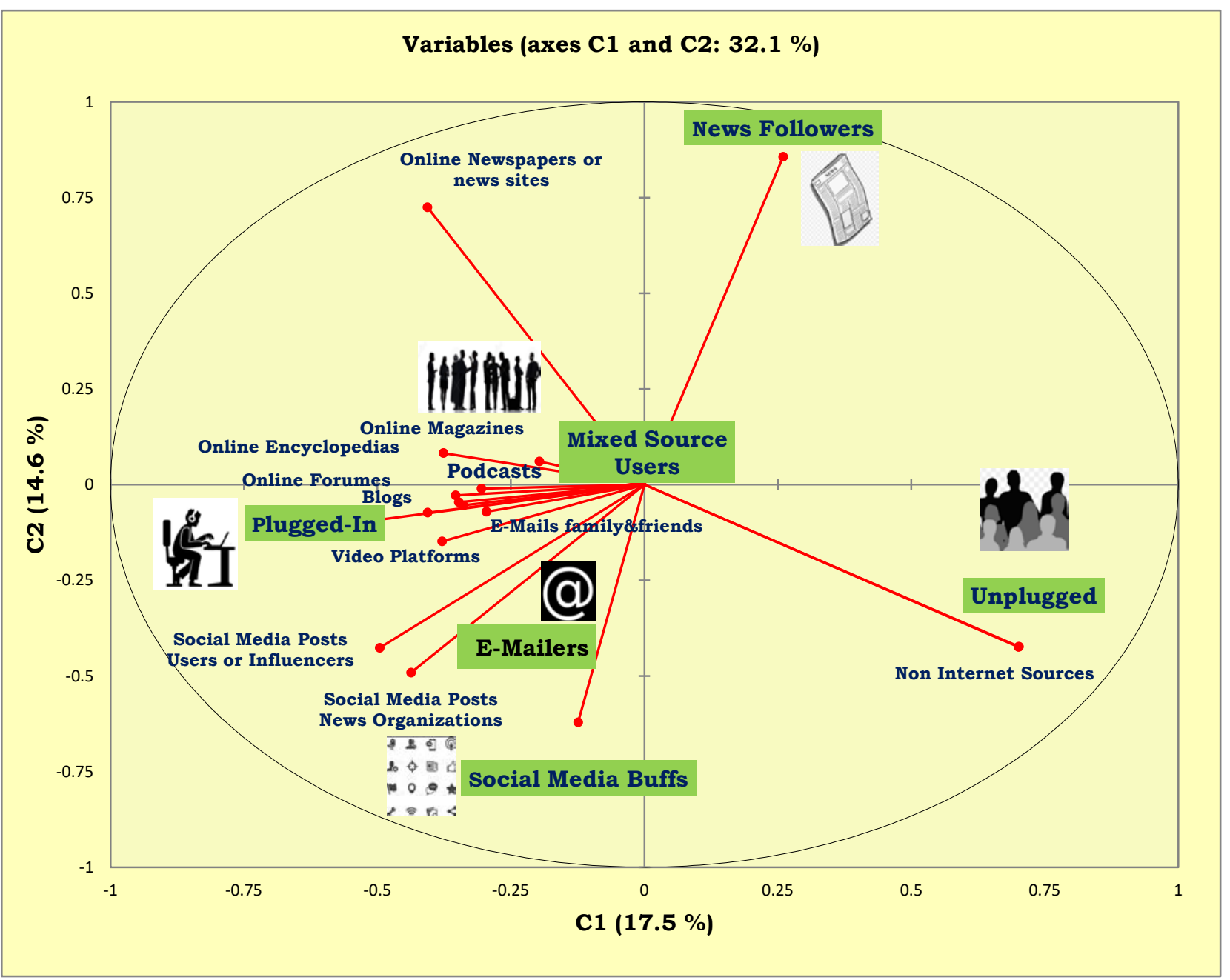

Source: CPSS-Series4 Survey, Statistics Canada, 2020 


\subsection{Segment Profile Summaries: Who Are They?}

The following are the summary descriptions of the population segments found in the CPSSSeries4 data:

\section{Segment 1 - Social Media Buffs (27\% representing 8.5 million adult Canadians), Segment Motto: "Social Media Influencers Know Their Stuff!"}

One in four Canadians may be regarded as a social media buff (27\%). To understand the pandemic, segment members heavily consume social media news and postings from social media influencers (66\% and 68\% respectively). Social media buffs were less stringent in terms of information verification compared to members of the other segments: only $58 \%$ consulted other sources as information check-ups or checked information for accuracy. Of those who did not check, $41 \%$ did not think of checking the information at the time while $38 \%$ indicated that "did not care to check". In terms of socio-demographic characteristics they tend to have an over-representation of younger individuals (39\% aged 35 years old or younger), females (57\%) and, in particular, had a child 18 years old younger living at home (43\%). About half (48\%) had attained a level of education equivalent to a high school diploma or below. About $17 \%$ reported either a fair or poor state of mental health and $15 \%$ moderate symptoms of generalized anxiety during the pandemic.

\section{Segment 2 - News Followers (33\% representing 10.1 Million adult Canadians), Segment Motto: "Track Those Headlines!"}

This segment is the largest (one out of three Canadians) and comprises individuals who consistently follow news and are up-to-date on current pandemic developments in Canada and around the world. Online news and online magazines are their preferred sources of information (93\% and 7\% respectively). They are not, however, necessarily concerned with checking the information provided by the news services: only $56 \%$ checked the accuracy of this information. The majority of them (62\%) who did not checked declared that they did not do so because "they trusted the source". About $64 \%$ of them detected false information in social media at least once a week and only 35\% realized that the original information presented was, in fact, false. There was a slight over-representation of males in this particular segment $(52 \%)$ as well individuals in married or common-law relationships (63\%). About 13\% reported either a fair or poor state of mental health and $11 \%$ moderate symptoms of generalized anxiety during the pandemic.

\section{Segment 3 - Unplugged (10\% representing 3.0 million adult Canadians), Segment Motto: "I've Got my Own Info Sources about the Pandemic!"}

These individuals are social media-"averse" and primarily obtain their pandemic information from personal contacts and other traditional media such as printed newspapers, books, T.V and/or radio. They tend to be a relatively older cohort (43\% were aged 65 years old and over), females (55\%) and half (50\%) reported having an educational equivalent to a high school diploma or below. Rural residents were also over-represented in this segment (23\%). About $61 \%$ were not employed and possibly retired at the time of the survey. About $16 \%$ reported 
10

either a fair or poor state of mental health and 14\% moderate symptoms of generalized anxiety during the pandemic.

\section{Segment 4 - Plugged-In (7\% representing 2.3 million adult Canadians), Segment Motto: "Did You Read the Last Blog?"}

Members of this elite segment are the "savants" of social media and utilize it intensively through its different forms and manifestations. They obtain and share information about the pandemic through all 10 of the social media activities recorded in the survey. About $76 \%$ of them reported following on-line news, $58 \%$ social media influencers and $55 \%$ social media news. A notable feature is their subscription to podcasts (47\%), video platforms (39\%) and online discussion forums (45\%). Plugged-In segment members were the more stringent in terms of information verification: $89 \%$ consulted other sources as information validation and read thoroughly the articles presented to them (71\%). They also were among the most comprehensive in terms of detecting false information at least once a week (73\%) and also in realizing that some original information presented was, in fact, false (49\%). Individuals of this segments tend to be younger (51\% were aged 35 years old or younger), single (41\%) and $41 \%$ had attained a level of education equivalent to a bachelor university or above. About $62 \%$ were employed at work for at least part of the reference weekk. In the terms of mental health, one in four segment members $(25 \%)$ reported either a fair or poor state of mental health and $17 \%$ were classified as having moderate or severe symptoms of generalized anxiety.

\section{Segment 5 - E-mailers (7\% representing 2.2 Million Adult Canadians), Segment Motto: "My People Know Better!"}

E-mailers do not rely only on pandemic-related information originating from e-mails sent by family and friends (62\%) but also from media such as online news (72\%), social media news $(45 \%)$ and online media encyclopedias (42\%). Segment members were not as stringent in terms of information validation as those in the Plugged-In segment but did some verifications of their own: $78 \%$ consulted with other sources while $69 \%$ checked the accuracy of the information. About 41\% validated this information through family, friends and their social network. A notable feature about this segment is an over-representation of males (58\%) and foreign-born (40\%). About 12\% reported either a fair or poor state of mental health while 11\% were classified as having either a moderate or severe symptoms of generalized anxiety.

\section{Segment 6 - Mixed Source Users (16\% representing 5.0 Million Adult Canadians), Segment Motto: "Better Info Means More Choices!"}

Members of this segment are similar to the first Social Media Buff segment but differ from them because of their somewhat higher use of video-based platforms (15\%) to comprehend the pandemic. They also had some communalities with News Followers population segment: everyone (100\%) reported accessing online news while 70\% reported obtaining information from social media influencers. About 78\% of mixed sources users undertook some kind of information verification through consultation with other sources of information. In terms of socio-demographic characteristics they display some over-representation of younger media users (36\% aged 35 years old or under), females (54\%) and more educated individuals (35\% had an equivalent diploma to a bachelor university or above). About 18\% of the Mixed Sources 
11

segment members reported a fair or poor level of mental health while $13 \%$ were classified as having a moderate or high symptoms of generalized anxiety at the time of the survey.

Table 2: Social Media Use Scales (Average Score) Reported by the Six Population Segments, Canada 2020

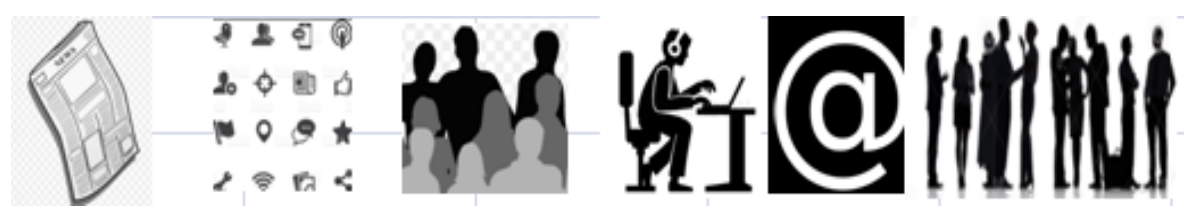

\begin{tabular}{|c|c|c|c|c|c|c|c|}
\hline Social Media Use Items & 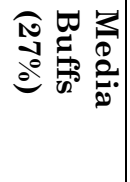 & 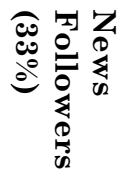 & 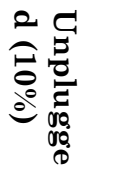 & 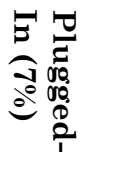 & 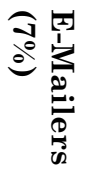 & 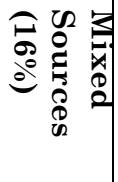 & 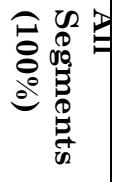 \\
\hline 1. Online News & $25 \%$ & $93 \%$ & $\mathbf{0} \%$ & $76 \%$ & $72 \%$ & $100 \%$ & $63 \%$ \\
\hline 2. Social Media News & $66 \%$ & $\mathbf{0 \%}$ & $\mathbf{0 \%}$ & $55 \%$ & $45 \%$ & $70 \%$ & $35 \%$ \\
\hline 3. Social Media Influencers & $68 \%$ & $\mathbf{0} \%$ & $\mathbf{0} \%$ & $58 \%$ & $38 \%$ & $31 \%$ & $30 \%$ \\
\hline 4. Non-Internet Sources & 0\% & $\mathbf{0 \%}$ & $100 \%$ & $\mathbf{0 \%}$ & 0\% & 0\% & $10 \%$ \\
\hline 5. Online Magazines & $1 \%$ & $7 \%$ & $\mathbf{0 \%}$ & $31 \%$ & $26 \%$ & $15 \%$ & $9 \%$ \\
\hline 6. Video Platforms & $12 \%$ & $\mathbf{0} \%$ & $\mathbf{0} \%$ & $39 \%$ & $16 \%$ & $11 \%$ & $9 \%$ \\
\hline 7. Online Forums & 0\% & $2 \%$ & $\mathbf{0} \%$ & $45 \%$ & $6 \%$ & $3 \%$ & $5 \%$ \\
\hline 8. E-Mails & 0\% & $\mathbf{0 \%}$ & $\mathbf{0} \%$ & $7 \%$ & $62 \%$ & $\mathbf{0 \%}$ & $5 \%$ \\
\hline 9. Online Encyclopedias & 0\% & $\mathbf{0} \%$ & 0\% & $10 \%$ & $42 \%$ & $0 \%$ & $4 \%$ \\
\hline 10. Podcasts & 0\% & 0\% & $0 \%$ & $47 \%$ & 0\% & $0 \%$ & $4 \%$ \\
\hline 11. Online Blogs & $0 \%$ & $0 \%$ & $0 \%$ & $18 \%$ & $0 \%$ & $0 \%$ & $1 \%$ \\
\hline
\end{tabular}

Source: CPSS-Series4 Survey, Statistics Canada, 2020 
Chart 3: Information Verification Activities of Population Segments, Social Media Users, Canadian Adults, 2020
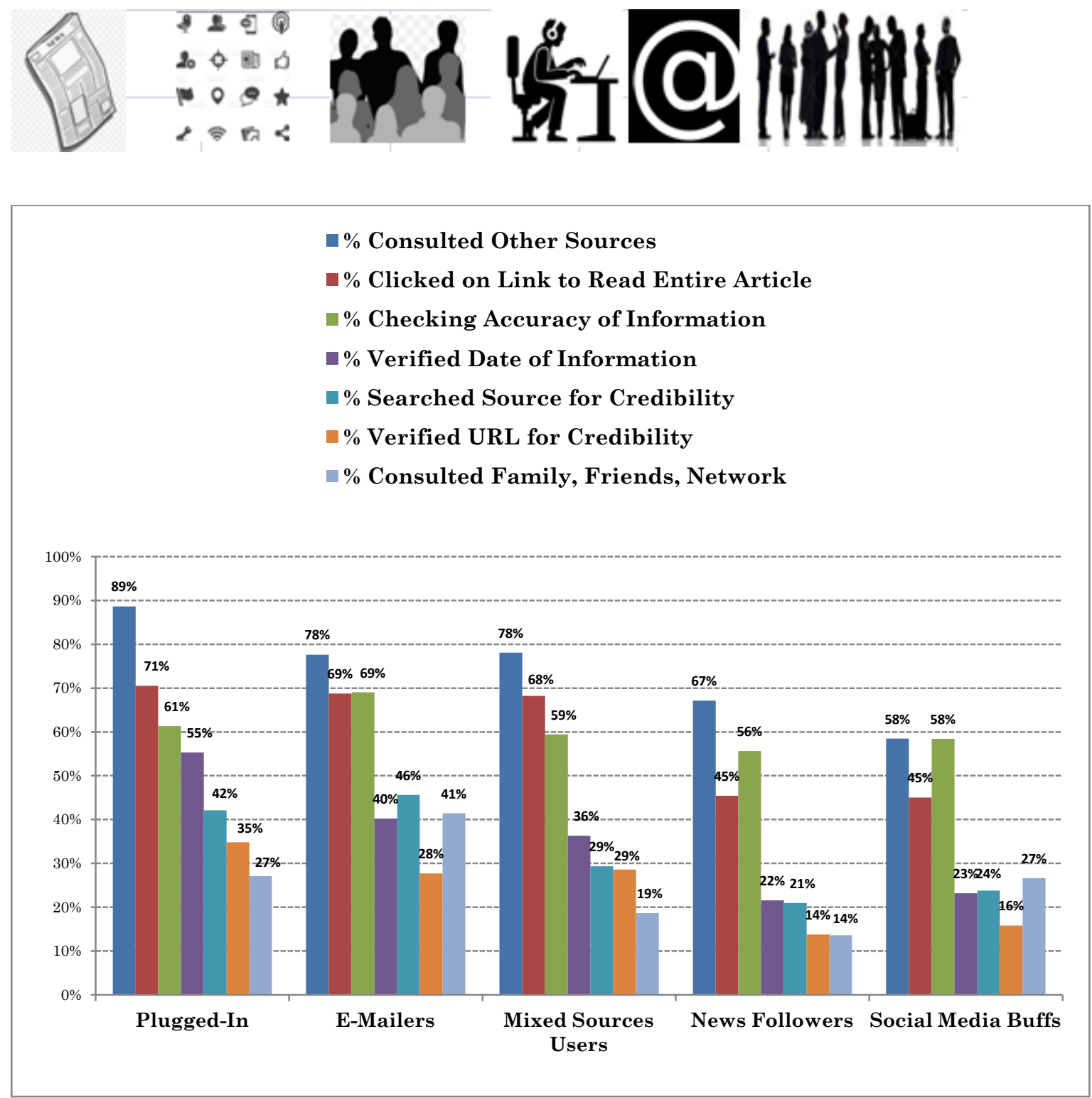

Source: CPSS-Series4 Survey, Statistics Canada, 2020 
Chart 4: Information Validation of Population Segments, Social Media Users, Canadian Adults, 2020
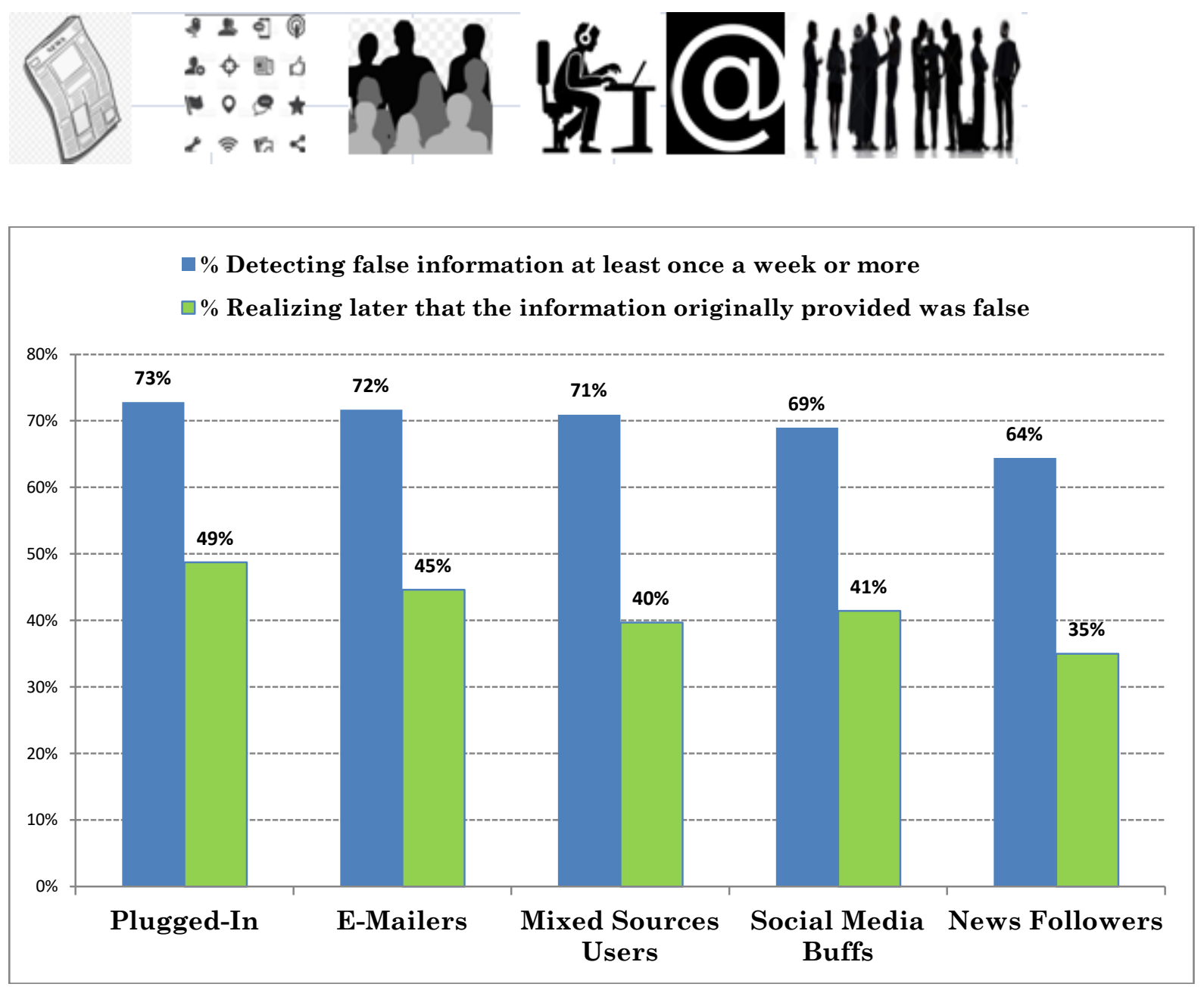

Source: CPSS-Series4 Survey, Statistics Canada, 2020 
Table 3: Socio-Demographic, Residential, Employment and Health Profiles of the Six Population Segments, Canada 2020

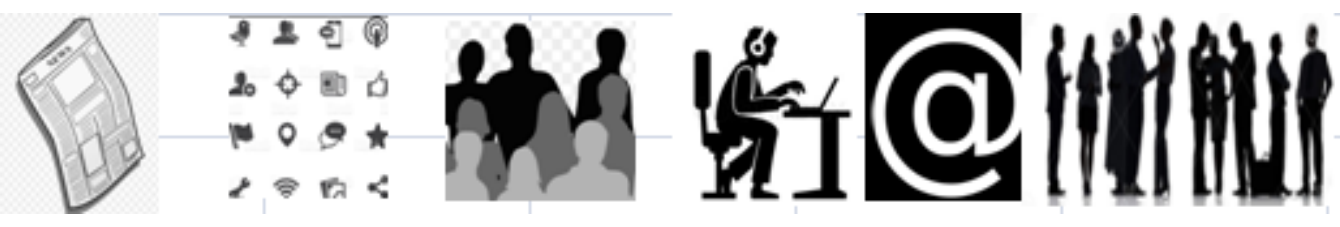

\begin{tabular}{|c|c|c|c|c|c|c|c|}
\hline $\begin{array}{l}\text { Socio-Demographic, } \\
\text { Residential, Employment } \\
\text { and Mental Health } \\
\text { Profiles }\end{array}$ & 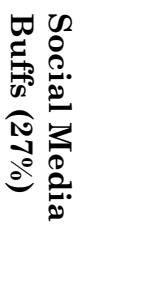 & 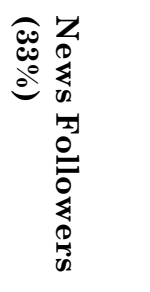 & 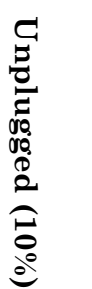 & 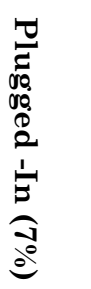 & 递 & 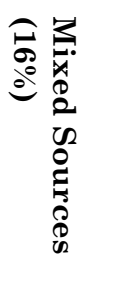 & 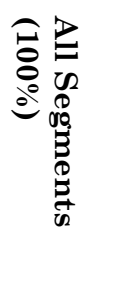 \\
\hline$\% 35$ years old or under & $39 \%$ & $26 \%$ & $5 \%$ & $51 \%$ & $28 \%$ & $36 \%$ & $31 \%$ \\
\hline$\% 65+$ years old & $15 \%$ & $25 \%$ & $43 \%$ & $8 \%$ & $25 \%$ & $17 \%$ & $21 \%$ \\
\hline$\%$ Female & $56 \%$ & $48 \%$ & $55 \%$ & $39 \%$ & $42 \%$ & $54 \%$ & $51 \%$ \\
\hline$\%$ Married or Common Law & $57 \%$ & $63 \%$ & $66 \%$ & $51 \%$ & $62 \%$ & $63 \%$ & $61 \%$ \\
\hline$\%$ Single Marital status & $34 \%$ & $24 \%$ & $9 \%$ & $41 \%$ & $30 \%$ & $29 \%$ & $28 \%$ \\
\hline$\%$ Foreign-born & $25 \%$ & $24 \%$ & $16 \%$ & $24 \%$ & $40 \%$ & $22 \%$ & $24 \%$ \\
\hline $\begin{array}{l}\text { \% Living in a household with } \\
\text { a child } 18 \text { years old or under }\end{array}$ & $43 \%$ & $27 \%$ & $11 \%$ & $38 \%$ & $28 \%$ & $37 \%$ & $33 \%$ \\
\hline \% Urban Residence & $82 \%$ & $86 \%$ & $77 \%$ & $89 \%$ & $93 \%$ & $82 \%$ & $84 \%$ \\
\hline $\begin{array}{l}\text { \% High School Diploma or } \\
\text { less }\end{array}$ & $48 \%$ & $36 \%$ & $50 \%$ & $31 \%$ & $32 \%$ & $29 \%$ & $39 \%$ \\
\hline $\begin{array}{l}\text { \% University education } \\
\text { equivalent to bachelor or } \\
\text { more }\end{array}$ & $20 \%$ & $33 \%$ & $15 \%$ & $41 \%$ & $37 \%$ & $35 \%$ & $29 \%$ \\
\hline $\begin{array}{l}\text { \% Living in apartment } \\
\text { building }\end{array}$ & $18 \%$ & $21 \%$ & $17 \%$ & $21 \%$ & $23 \%$ & $20 \%$ & $20 \%$ \\
\hline $\begin{array}{l}\text { \% Employed at work for at } \\
\text { least part of the reference } \\
\text { week }\end{array}$ & $63 \%$ & $\mathbf{5 5} \%$ & $37 \%$ & $62 \%$ & $51 \%$ & $66 \%$ & $\mathbf{5 7 \%}$ \\
\hline $\begin{array}{l}\text { \% Moderate or Severe } \\
\text { Symptoms of Generalized } \\
\text { Anxiety }\end{array}$ & $15 \%$ & $11 \%$ & $14 \%$ & $17 \%$ & $11 \%$ & $13 \%$ & $13 \%$ \\
\hline $\begin{array}{l}\text { \% Poor or Fair Level of } \\
\text { Mental Health }\end{array}$ & $17 \%$ & $13 \%$ & $16 \%$ & $25 \%$ & $12 \%$ & $18 \%$ & $16 \%$ \\
\hline
\end{tabular}

Source: CPSS-Series4 Survey, Statistics Canada, 2020 


\subsection{Reflections}

Given that the social and non-social media use are often city or region-specific, more geographically focused studies are desirable. It should be noted that the available public version of the CPSS-Series4 survey, regrettably, did not contain provincial or territorial breakdowns and was limited to individual reporting during the "second" phase of the pandemic. In the subsequent phases of the pandemic, shifts in the share of segment composition are likely to occur. More frequent surveys carried out by Statistics Canada and/or other data collection agencies may yield, in the future, important information on the common transitions of individuals from one cluster to another.

How can health and other social agencies better reach the six population segments of media users identified in this study? The answer to this question can be framed in terms of the type and frequency of information they receive and their exposure to inaccurate, misleading information about the virus, its transmission and its treatments. Public health officials can mitigate the impact of misinformation by calling attention to it and directing users to verified sources. Previous studies have found that inaccurate and misleading health-related social media posts have been more popular than those containing verified, factual information (e.g. Sharma et al., 2017). This is further compounded by the presence of algorithms on social media platforms and other platforms that push content to users based on their preferences and previous online behaviour (Pariser, 2012). In particular, when users are unaware of the existence or effect of algorithms and do not carefully consider the source or accuracy of the information they access, this could lead to poor and uninformed health-related decision-making (Holone, 2016).

For Social Media Buffs, social media is not merely a source of information, but also a primary source of entertainment and escape from the boredom and "mundanity" that resulted from lockdown restrictions (Presky, 2020). Among other things, it allows users to connect and share experiences with those that they may not be able to interact with in person due to confinement restrictions potentially reducing feelings of self-isolation. Despite their avid use of social media, Social Media Buffs as less likely to verify the accuracy of information than other segments. This may have serious health implications say for vaccine distribution and administration as people might refuse a vaccine on the basis of something they've read online. Public health officials may need to harness the social power of celebrities and social media influencers to effectively target this segment. ${ }^{9}$

The psychographics of the News followers segment in Canada is also interesting to highlight. That online news sources were more frequently consulted than Social Media News and Social Media Influencers is consistent with findings from other recent studies (i.e. Parsons Leigh et al., 2020). This does not, however, provide a full picture on what sources Canadians are using to obtain information about the COVID-19 pandemic because it does not account for the behaviour of specific age-cohorts within this population segment. For example, while in 2018 $75 \%$ of Canadians over the age of 15 reported using social media applications or websites, this

\footnotetext{
${ }^{9}$ For example, the Mailman School of Public Health at Columbia University worked with actors from the film Contagion to release public service announcements (PSAs) about dispel misinformation about public health measures after the onset of the virus in North America. The PSAs can be viewed at https://www.publichealth.columbia.edu/control-contagion.
} 
number was higher for Canadians between the ages of 15-24 years old (92.4\%) and 25-44 years old (88.1\%) and significantly lower for Canadians 65 years old or over (45.6\%).10

Traditional non-digital media continue to play an important role in the dissemination of public health information for members of the Unplugged segment, especially for older and rural residents. Further, a small portion of the population reported receiving regular information updates from friends and family via e-mail. Public health officials and other social agencies will therefore need to continue to traditional forms of digital and non-digital media. Lower internet and social media use for the Unplugged population segment could be, at least in part, attributed to a lack or lower level of access to such services and platforms stemming from the absence of crucial digital infrastructure and/or lower levels of digital literacy skills. This digital divide has been connected demographic factors such as geographic location (i.e. rural vs urban), education and age (Haight, Quan-Haase, \& Corbett, 2014), populations overrepresented in Unplugged segment. In the absence of internet access and/or social media use, it may be difficult to communicate information to segment members quickly. These individuals may have limited access to in-person social networks due to quarantine restrictions, with limited opportunities for online social interaction thereby impacting their mental health. Data collected from social media use and internet searches can be and has been used to track disease outbreaks (Schmidt, 2012). Lower levels of social media use could impact the ability of public health officials to predict disease outbreaks.

Members of the elite "Plugged-In" segment consulted the widest variety of internet sources for information about the pandemic and were vigilant when it came to verifying that information. This likely meant that they spent the most time online following news of the pandemic, putting members in this group at a higher risk of information overload, "cyberchondria", and negative mental health impacts (Farooq, Laato, \& Islam, 2020). It also became a primary destination for education and employments as many students and workers moved online, further increasing "screentime" and the likelihood of information overload or screen fatigue. Similar observations can be made with respect to the members of the "Mixed Sources" segment identified in this analysis.

Finally, with respect to E-Mailers, this population segment relies more heavily on word of mouth communication from peers and close contacts than others. As word of mouth communication is perceived to be more reliable and trustworthy than other sources, it is surprising that $69 \%$ of $\mathrm{E}$ mailer segment members engaged in fact-checking. Public health officials may be able to capitalize on word-of-mouth communication by encouraging readers to share the information with friends and family not only via social media but also by e-mail and other forms of communication. Lower levels of social media use can be linked to the reduced levels of poor mental health and anxiety reported by segment members. They maintained contact with their network via email while minimizing the possibility for information overload.

Overall, this study suggests that the media users in Canada during the COVID-19 pandemic constitute a very diverse group of individuals. They are constantly exposed to a steady flow of information, opinions, advice and judgments originating from individuals and/or agencies which attempt to make sense of the epidemic and its wider societal impacts. Members of the six population segments of media users are unique in terms of their digital or non-digital

\footnotetext{
${ }^{10}$ Statistics Canada. Table 22-10-0084-01 Online activities by gender, age group and highest certificate, diploma or degree completed, https://www150.statcan.gc.ca/t1/tbl1/en/tv.action?pid=2210008401, DOI: https://doi.org/10.25318/2210008401-eng
} 
17

preferences but share a common preoccupation in making sense of the current environment and developing coping mechanisms to survive the pandemic. In this light, market segmentation may be a useful tool for decision makers to categorize population members by their typical attitudinal traits and, by doing so, facilitate better public campaigns directed at the various population segments, help design messages, and implement changes that can promote more efficient ways to deal with their target audiences.

\subsection{References}

Chin-Feng, L. (2002). Segmenting Customer Brand Preference: Demographic or Psychographic, Journal of Product \& Brand Management, Vol. 11 (4) pp. 249 - 268.

Drouin, M; McDaniel; B. Pater, J. and Toscos,T (2020). How Parents and Their Children Used Social Media and Technology at the Beginning of the COVID-19 Pandemic and Associations with Anxiety, Cyberpsychology, Behaviour and Social Networking, Vol 23(11).

Farooq, A.; Laato, S., and Islam, A.K.M.N. (2020). Impact of Online Information on Self-Isolation Intention During the COVID-19 Pandemic: Cross-Sectional Study, Journal of Medical Internet Research, Vol. 22 (5), DOI: 10.2196/19128.

Grover, R and Vriens, M. (2006). A Guide to the Design and Execution of Segmentation Studies, The Handbook of Marketing Research, Sage Publishing.

Haight, M.; Quan-Haase, A., and Corbett, B.A. (2014). Revisiting the Digital Divide in Canada: The Impact of Demographic Factors on Access to the Internet, Level of Online Activity, and Social Networking Site Usage, Information, Communication \& Society, Vol 17(4), pp.503-519.

Holone, H. (2016). The Filter Bubble and its Effect on Online Personal Health Information, Croatian Medical Journal, Vol. 57(3), 298-301, DOI: doi:10.3325/cmj.2016.57.298.

Mehdi, M; Kammer, J.; Analytis, P. and Neth, H. (2013). Social Influence and the Collective Dynamics of Opinion Formation, PLoS ONE (8)-Issue 11, Public Library of Science, DOI: http://dx.doi.org/10.1371/journal.pone.0078433

Pariser, E. (2012). The Filter Bubble: How the New Personalized Web is Changing What We Read and How We Think, Penguin Books.

Parsons Leigh J, Fiest K, Brundin-Mather R, Plotnikoff K, Soo A, Sypes EE, et al. (2020) A National Cross-sectional Survey of Public Perceptions of the COVID-19 Pandemic: Self- Reported Beliefs, Knowledge, and Behaviors. PLoS ONE 15(10): e0241259. https://doi.org/10.1371/ journal.pone.0241259

Presky, N. (2020). TikTok has exploded in popularity - is it the perfect antidote to isolation?. Stylist, April 15. Available at https://www.stylist.co.uk/opinion/tiktok-videos-dances-songschallenges-coronavirus-popularity-social-media/379053 (accessed 22 November 2020).

Punj, G., \& Stewart, D. (1983). Cluster Analysis in Marketing Research: Review and Suggestions for 
18

Application. Journal of Marketing Research, 20, pp. 134-148.

Salkind, N.J., and Rasmussen, K. (2010). k-Means Cluster Analysis, Encyclopedia of Measurement and Statistics: Sage Publishing

Schmidt, C.W. (2012). Trending now: Using Social Media to Predict and Track Disease Outbreaks. Environmental Health Perspectives, Vol. 120(1), A30+.

https://ink.gale.com/apps/doc/A278773889/AONE?u=otta77973\&sid=AONE\&xid=96d02f51

Sharma, M.; Yadav, K.; Yadav, N., and Ferdinand, K.C. (2017) Zika Virus Pandemic - Analysis of Facebook as a Social Media Health Information Platform. American Journal of Infection Control; (45), 301-2.

Tynan, C.A. and Drayton, J.(1987). Market Segmentation. Journal of Marketing Management (2) No.3, pp.301-335.

World Health Organization-WHO. (2020) . Mental Health and Psychosocial Considerations During COVID-19 Outbreak; World Health Organization: Genève, Switzerland, 2020.

World Economic Forum-WEF (2019) Who Uses Social Media the Most? Report retrieved from https://www.weforum.org/agenda/2019/10/social-media-use-by-generation, November 13,2020.

Wiederhold, B.K.(2020) Using Social Media to Our Advantage: Alleviating Anxiety During a Pandemic. Cyberpsychology, Behavior, and Social Networking 2020; (23):197-198.

Valkenburg, P.M and Piotrowski, J.T. (2017) Plugged In: How Media Attract and Affect Youth Yale University Press, New Haven. 


\section{Within Class Sum of Squares Variation Ratio(WSS)}

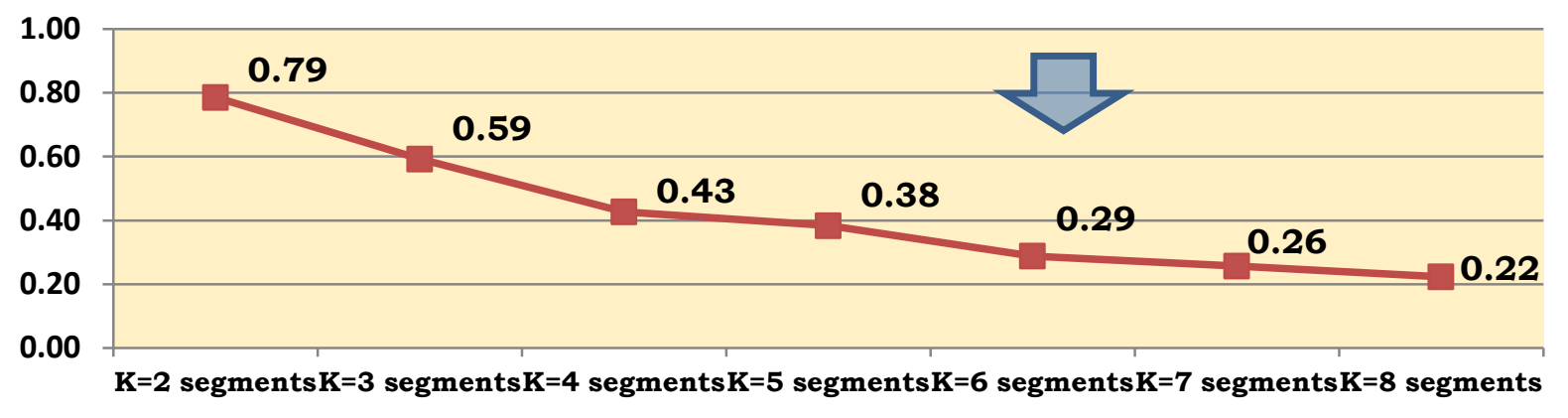

Source: CPSS-Series4 Survey, Statistics Canada, 2020

Table A-2:ANOVA F tests predicting Socio-Demographic, Residential, Employment and Mental Health Related Characteristics of CPSS-Series4 Survey Respondents

\begin{tabular}{|c|c|c|c|c|c|c|}
\hline ANOVA Test Results & SS & d.f & Mean Square & F Ratio & Sig. & $\begin{array}{c}\mathbf{R} \\
\text { Square }\end{array}$ \\
\hline Age Groups & 1087241.8 & 5 & 217448.4 & 468097.0 & 0.000 & 0.07 \\
\hline $\begin{array}{l}\text { Educational Level of } \\
\text { Respondent }\end{array}$ & 707630.2 & 5 & 141526.0 & 217975.4 & 0.000 & 0.04 \\
\hline Sex of respondent & 93248.4 & 5 & 18649.7 & 75577.9 & 0.000 & 0.01 \\
\hline Type of dwelling & 162374.2 & 5 & 32474.8 & 23322.3 & 0.000 & 0.00 \\
\hline $\begin{array}{l}\text { Child under } 18 \text { on July } \\
20,2020 \text { resides in } \\
\text { dwelling }\end{array}$ & 277588.1 & 5 & 55517.6 & 261203.0 & 0.000 & 0.04 \\
\hline $\begin{array}{l}\text { Marital status of } \\
\text { respondent }\end{array}$ & 775870.3 & 5 & 155174.1 & 92969.4 & 0.000 & 0.02 \\
\hline Immigration status & 67574.0 & 5 & 13514.8 & 74686.4 & 0.000 & 0.01 \\
\hline Rural/Urban indicator & 32055.0 & 5 & 6411.0 & 50350.6 & 0.000 & 0.01 \\
\hline $\begin{array}{l}\text { Severity of } \\
\text { Generalized Anxiety }\end{array}$ & 495305.2 & 5 & 99061.0 & 82468.8 & 0.000 & 0.01 \\
\hline $\begin{array}{l}\text { Perceived mental } \\
\text { health }\end{array}$ & 267126.3 & 5 & 53425.3 & 48760.3 & 0.000 & 0.01 \\
\hline Employment status & 1252968.3 & 5 & 250593.7 & 125971.5 & 0.000 & 0.02 \\
\hline
\end{tabular}

